\title{
Mutations in the cardiac troponin $T$ gene show various prognoses in Japanese patients with hypertrophic cardiomyopathy
}

\author{
Etsuko Fujita - Toshio Nakanishi - Tsutomu Nishizawa • \\ Nobuhisa Hagiwara • Rumiko Matsuoka
}

Received: 2 April 2012/Accepted: 15 February 2013/Published online: 14 March 2013

(C) The Author(s) 2013. This article is published with open access at Springerlink.com

\begin{abstract}
Hypertrophic cardiomyopathy (HCM) is an autosomal dominant disorder resulting from mutations in genes for at least 15 various sarcomere-related proteins including cardiac $\beta$-myosin heavy chain, cardiac myosinbinding protein $\mathrm{C}$, and cardiac troponin $\mathrm{T}$. The troponin $\mathrm{T}$ gene (TNNT2) mutation has the third incidence of familial HCM, and the genotype-phenotype correlation of this gene still remains insufficient in Japanese familial HCM. Therefore, in the present study, we focused on screening the TNNT2 mutation in 173 unrelated Japanese patients with familial HCM, and found three reported mutations and a new mutation of TNNT2 in 11 individuals from four families. In these families, two individuals from one family had double mutations, Arg130Cys and Phe110Ile, six individuals from two other families had an
\end{abstract}

E. Fujita $\cdot$ N. Hagiwara

Department of Cardiology, Tokyo Women's Medical University, Tokyo, Japan

T. Nakanishi · R. Matsuoka

Department of Pediatric Cardiology, Tokyo Women's Medical University, Tokyo, Japan

T. Nishizawa $\cdot$ R. Matsuoka

International Research and Educational Institute for Integrated Medical Sciences (IREIMS), Tokyo Women's Medical

University, Tokyo, Japan

\section{R. Matsuoka}

Division of Genomic Medicine, Institute of Advanced Biomedical Engineering and Science, Graduate School of Medicine, Tokyo Women's Medical University, Tokyo, Japan

\section{R. Matsuoka ( $\square)$}

International Center for Molecular, Cellular, and Immunological Research (IMCIR), Tokyo Women's Medical University,

8-1 Kawada-cho, Shinjuku-ku, Tokyo 162-8666, Japan

e-mail: rumiko@imcir.twmu.ac.jp
Arg92Trp mutation, and one individual of another family had a new mutation, Ile79Thr, of TNNT2. The phenotype of each family was often different from reported cases, even if they had the same genetic mutation. In addition, families with the same genetic mutation showed a similar trend in the phenotype, but it was not exactly the same. However, sudden death in youth was observed in all of these families. Although the type of genetic mutation is not useful for predicting prognosis in HCM, the possibility of sudden cardiac death remains. Therefore, the prognosis of individuals bearing the TNNT2 mutation with familial HCM should be more carefully observed from birth.

Keywords Familial hypertrophic cardiomyopathy · TNNT2 gene - Mutation P Phenotype-genotype

\section{Introduction}

Hypertrophic cardiomyopathy (HCM) is characterized by left and/or right ventricular hypertrophy, with predominant involvement of the interventricular septum in the absence of other causes of hypertrophy, such as hypertension, valvular heart disease, or metabolic disease [1-7].

Familial HCM is an autosomal dominant disorder caused by mutations in genes that encode sarcomere proteins. It has been reported that at least 15 genes are implicated in 55-70\% of $\mathrm{HCM}$, and the major genes causing HCM include cardiac $\beta$-myosin heavy chain (MYH7), $\alpha$-tropomyosin, cardiac troponin $\mathrm{T}$ (TNNT2), cardiac myosin-binding protein $\mathrm{C}$ (MYBPC3), cardiac troponin I (TNNI3), cardiac myosin regulatory light chains (MYL2), and cardiac myosin essential light chains (MYL3) $[1,4,5,8-11]$. 
Cardiac troponin $\mathrm{T}$ is a thin-filament protein that takes part in muscle contraction. The troponin complex on the actin filament regulates the force and velocity of muscle contraction. Troponin $\mathrm{C}$ functions as a calcium receptor while troponin I inhibits adenosine triphosphatase (ATPase) activity when bound to actin. Troponin $\mathrm{T}$ fixes the troponin group to tropomyosin. During relaxation, the troponin group is bound to actin and tropomyosin, blocking the interaction of myosin and actin [12].

TNNT2 was mapped to chromosome 1q32. Mutations of TNNT2 were thought to account for approximately $15 \%$ of familial HCM, with most missense mutations located in exons 8-16 [3], and were associated with a particularly severe form of the disease characterized by a poor overall prognosis with a high incidence of sudden death despite only mild left ventricular hypertrophy (LVH) [1-4]. Most TNNT2 mutations of familial HCM alter the contractile properties of cardiac muscle, especially the $\mathrm{Ca}^{2+}$ sensitivity of force development and ATPase activity in vitro and in vivo [13-17].

Previous reports have suggested that there is a more consistent relationship between certain genetic mutations and clinical outcome, allowing for the classification of "benign" and "malignant" mutations [18-30]. For example, a favorable prognosis has been reported in patients with a Phe110Ile mutation of the TNNT2 mutation (in 16 individuals of 6 Japanese families) [19, 20]. From these data, genetic analysis and determination of genotype were thought to be important for assisting with patient management.

However, these findings were based on limited experience; to date, only 30 different mutations have been identified in TNNT2 [9-11, 18]. In addition to this genetic diversity, the phenotypic expression of these mutations varies considerably, ranging from asymptomatic individuals with a normal life expectancy to those with sudden cardiac death or the need for an early heart transplant. Clinical parameters such as the degree of LVH, the presence or absence of a left ventricular outflow tract gradient, and electrophysiology testing have not been predictive markers of poor prognosis [1-5]. More recently, it was reported that late gadolinium enhancement with cardiac magnetic resonance can be a predictive marker of the ventricular arrhythmia and poor prognosis in HCM [31].

In recent years, mutation-specific risk stratification was considered to be not possible, but genetic test-based risk stratification seemed to be clinically informative [32].

The TNNT2 mutation has the third-ranked incidence of familial HCM, and the genotype-phenotype correlation of this gene still remains insufficient in Japanese familial HCM. Therefore, in the present study we focused on screening the TNNT2 mutation.

\section{Patients and methods}

Subjects

We genetically evaluated 173 patients (101 men and 72 women; 0-79 years old, median age 20 years) who were clinically diagnosed with familial HCM.

Pediatric patients with HCM were recruited from Tokyo Women's Medical University. Written informed consent was obtained from all study subjects in accordance with the Declaration of Helsinki. If patients were younger than 16 years, informed consent was given by their guardians. We assessed each patient by taking their history and performing a physical examination, and reviewed their medical records. All assessments were done with the approval of the Ethics Committees of Tokyo Women's Medical University.

The diagnosis of HCM was determined through clinical evaluation, chest radiography, electrocardiography, echocardiography, and cardiac catheterization based on current international consensus criteria.

Diseases of the heart, hypertension, valvular heart disease, or metabolic disease attributable to HCM were excluded from this study by pediatric cardiologists.

\section{Mutation screenings}

Genomic DNA was prepared from peripheral blood lymphocytes or lymphoblast cell lines transformed by the Epstein-Barr virus, as described previously [33]. TNNT2 coding regions and exon-intron boundaries, including regions approximately 30-100 bp upstream and downstream from the exons, were amplified from genomic DNA using primers, as described in previous reports [34, 35]. Genomic DNA (50 ng) was amplified through the use of primers designed from flanking intron sequences (Table 1).

Amplified products were purified using a MultiScreen polymerase chain reaction (PCR) plate (Millipore, Billerica, MA, USA) and directly sequenced using the ABIPRISM BigDye-terminator cycle sequencing reaction kit and ABI 3130xl genetic analyzer (Applied Biosystems, Foster City, CA, USA). When a mutation was detected, we confirmed that it was not presenting 363 Japanese normal chromosomes by direct sequencing. 
Table 1 Primers used for amplification of fragments from TNNT2

\begin{tabular}{lll}
\hline Exon & Forward $\left(5^{\prime}-3^{\prime}\right)$ & Reverse $\left(5^{\prime}-3^{\prime}\right)$ \\
\hline 2 & GAGCTCTTCTGAGGAAGGCA & CTACCCAGAATCCGAGGGAC \\
3 and 4 & CAGGGCAGCGTGGACTCCC & CCCAGGGCTCCCAGGATTT \\
5 & CCATTCTCTGCTCTGGGTTC & GTGCACATGGGAAAGCTGTTCT \\
6 & TAGGGCTTATCTGTGGGGAAGGC & CTTCCCTGGAAAGAGCACTG \\
7 & GAAATGGAAATCCACAGGGA & TACTGCACCCCGTTCCATCA \\
8 and 9 & CTCTAGGAAGGATCAGGGCCC & CTCACAAAAGGGATGGAGGA \\
10 & GCGATGTCACCTTCTCCCTA & CACCGCACCCGGCCAATA \\
11 & GGTTTCCAATCCTTTCCCCTAA & GCTGCAGTGGACACCTCATTC \\
12 & GCCTTTGTCTTCCTGCCTTCTC & CAGCCAGCCCAATCTCTTCACT \\
13 & ACAGGGAGGGGGCAATCTGGCC & CCCAGAGCAGATGCGGGCAGTG \\
14 & ACTGGGTGCTGCCGTCTGGTC & AAGGGGGCTGTTGGGGAATAGG \\
15 & CACTCAGCCCCCTTCTCC & AAGCTTCTCCGCCCCACATTTC \\
16 & GGCACCCCAGTCCTACCC & GTCCCCCTCAACAGCACTTTT \\
\hline
\end{tabular}

The PCR conditions of these genes were modified and fragments were analyzed by electrophoresis, as described previously [36, 37].

Proband patients bearing TNNT2 mutations were additionally examined for reported HCM mutations, the coding regions of $M Y H 7, M Y B P C 3, T N N I 3, \alpha$-tropomyosin, $M L Y 2, M L Y 3$, and all exons, and a promoter region of the $\alpha$-galactosidase A gene. Primer sequences and detailed PCR conditions for these additional analyses are available upon request. Reference sequences and single-nucleotide polymorphism information were obtained from the National Center for Biotechnology Information.

\section{Results}

Clinical report and DNA analysis

To investigate mutations of TNNT2, we performed DNA analysis in 173 unrelated Japanese patients with familial HCM. We identified three reported mutations and a new mutation of TNNT2 in 11 individuals from four families (A, B, C, D) (Table 2).

In family $\mathrm{A}$, all five members who carried or were suspected of having HCM also had arrhythmia. Four of them had blocks, including a complete atrioventricular block (CAVB) and complete right bundle branch block (CRBBB) (Fig. 1; II-1, 6, III-1, 2), and one had bradycardia. Two of them died suddenly (Fig. 1; I-2, III-1), and one was a ventricular fibrillation (Vf) survivor (Fig. 1; III-2). The proband (Fig. 1; III-2), aged 12 years, with sinus rhythm (SR) and a CRBBB, had an episode of Vf, and her elder brother (Fig. 1; III-1), aged 14, also with SR and a CRBBB, had died suddenly. Her father and her uncle had pacemakers implanted to treat complete AV blocks. Her mother and mother's family had no symptoms or abnormal findings. The proband and her brother and father (Fig. 1; III-2, III-1, I-2) showed mild LVH (maximum wall thickness $<20 \mathrm{~mm}$ ). All three members underwent cardiac catheterization, and showed significant left ventricular relaxation abnormalities.

DNA analysis showed that the proband and her elder brother had the double reported mutations, Arg130Cys and Phe110Ile, of TNNT2 (Fig. 1). Her father, who had arrhythmia and mild HCM, had the Phe110Ile mutation, and her mother (II- $6^{\prime}$ ), who had no symptoms or abnormal findings, had the Arg130Cys mutation.

In family B, 3 of 10 members who carried or were suspected of having HCM were thought to have obstructive hypertrophic cardiomyopathy. Two female members (Fig. 2; II-4, III-9) died suddenly at a young age. The proband (Fig. 2; III-7) showed apical hypertrophy and apical aneurysm at a comparatively young age. Her aunt (Fig. 2; II-4), who had a heart murmur, was thought to have hypertrophic obstructive cardiomyopathy (HOCM), and died when she was 19 years old. Her younger sister (Fig. 2; III-9) did not show obstructive HCM, but died suddenly when she was 21 years old. Her grandmother (Fig. 2; I-1) died suddenly at the age of 50 years. DNA analysis showed that the proband (Fig. 2; III-7), her son (Fig. 2; IV-3), and her cousin (Fig. 2; III-2), who carried HCM, had an Arg92Trp mutation of TNNT2.

In family C, the proband (Fig. 3; IV-3), her mother (Fig. 3; III-3), and her grandmother (Fig. 3; II-3) showed mild cardiac hypertrophy (maximum wall thickness $<20 \mathrm{~mm}$ ) and asymmetric septal hypertrophy, and her myocardial hypertrophy had been gradually increasing. Her mother was suspected of having a shifting dilated phase by recent cardiac magnetic resonance imaging (MRI). The proband (Fig. 3; IV-3) had symptomatic West syndrome following perinatal 


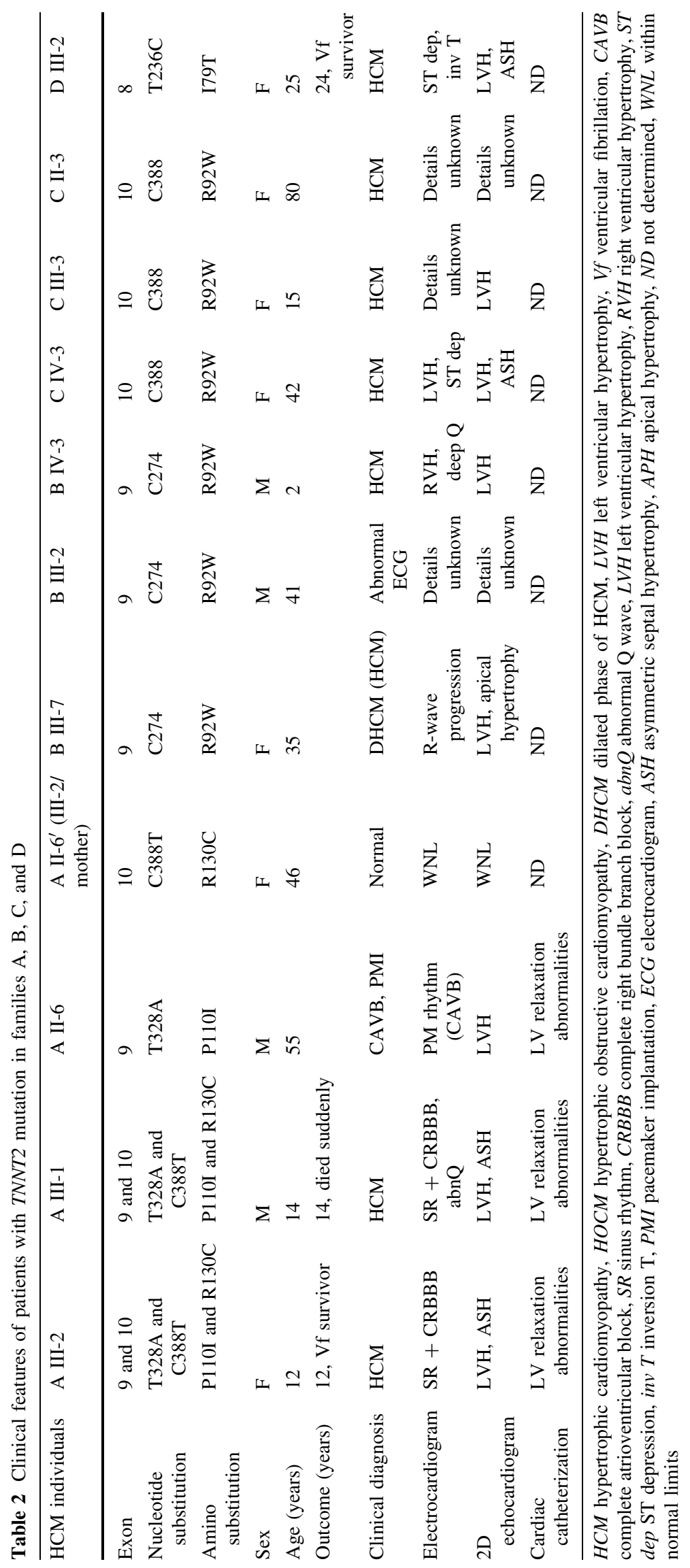


Fig. 1 Pedigree and phenotype of Family A. Pedigree with three generations (Roman Numerals), the propositus is denoted by an arrow. Further clinical data for family members is detailed in the table. HCM hypertrophic cardiomyopathy, $C A V B$ complete atrioventricular block, $P M I$ pacemaker implantation, $C R B B B$ complete right bundle-branch block, $V f$ ventricular fibrillation

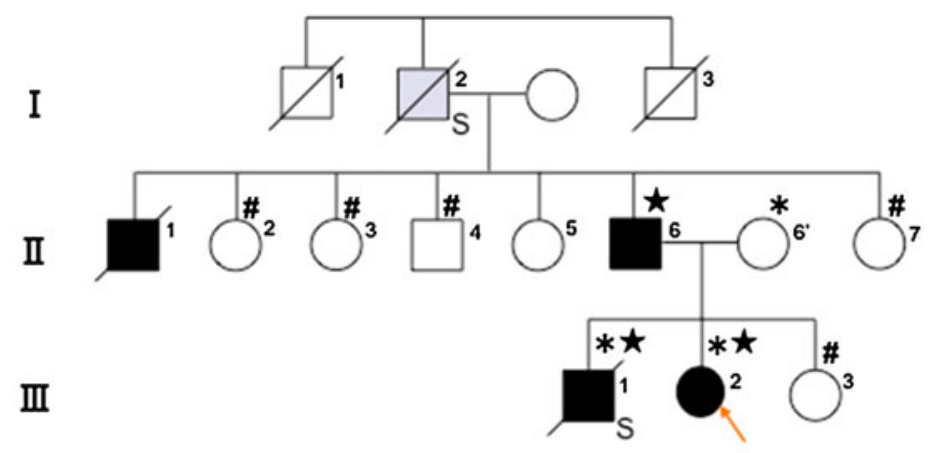

: proband
: hypertrophic cardiomyopathy
: asymptomatic proband
: hypertrophic cardiomyopathy suspected
\# $\quad$ : normal allele
$\star \quad$ : mutation allele Arg130Cys
$\mathrm{S} \quad$ : sudden death
$\quad$ : deceased

Fig. 2 Pedigree and phenotype of Family B. Pedigree with four generations (Roman Numerals), the propositus is denoted by an arrow. Further clinical data for family members is detailed in the table. HCM hypertrophic cardiomyopathy, HOCM hypertrophic obstructive cardiomyopathy, ECG electrocardiogram

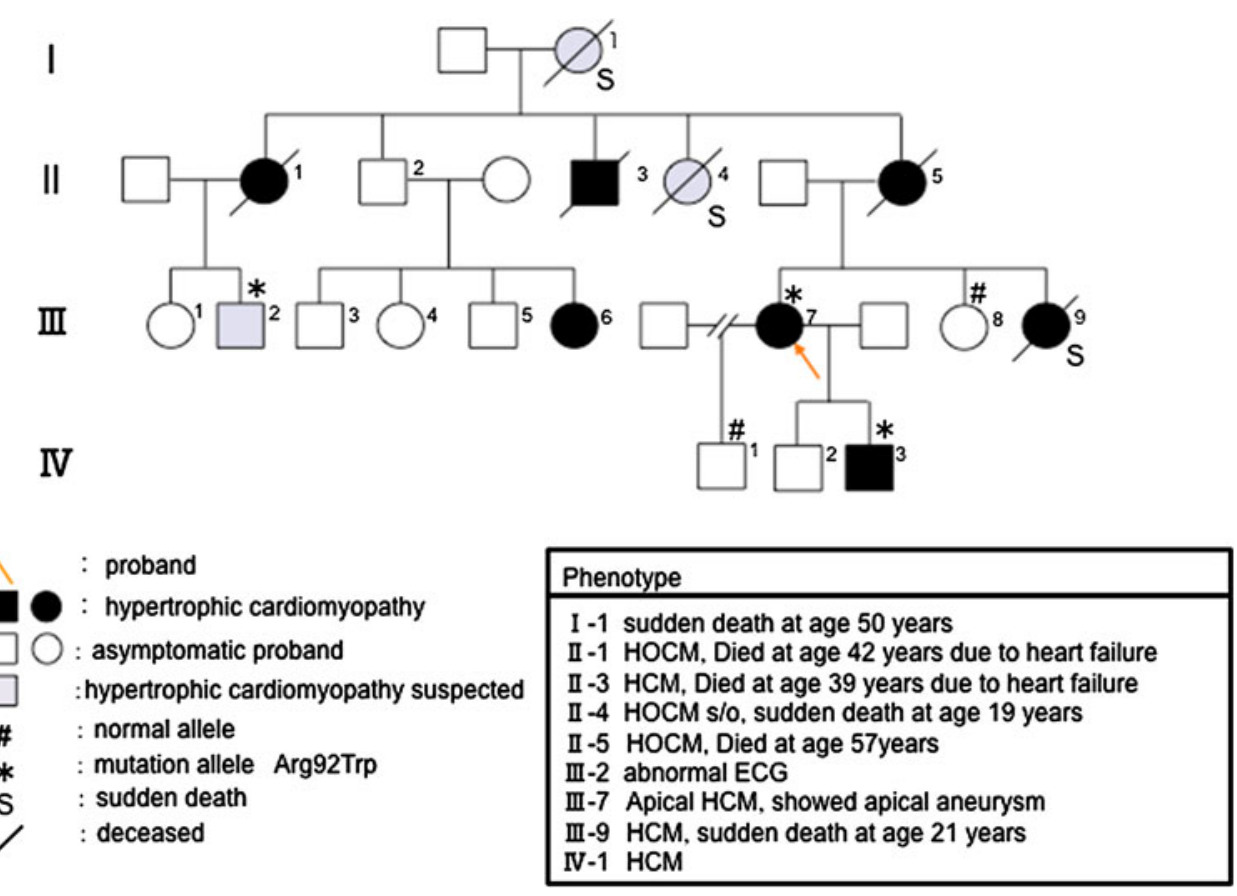

brain damage, and was treated with corticotropin. DNA analysis showed that the proband (Fig. 3; IV-3) and her mother (Fig. 3; III-3) had the Arg92Trp mutation of TNNT2.

In family $\mathrm{D}$, two of three members who carried or were suspected of having HCM died suddenly (Fig. 4; I-4, III-3), and one was a Vf survivor (Fig. 4; III-2). The proband (Fig. 4; III-2) had relatively strong cardiac hypertrophy (maximum wall thickness $>20 \mathrm{~mm}$ ), and cardiac standstill from ventricular fibrillation at the age of 24 years. Her cousin (Fig. 4; III-3) died suddenly at a young age (13 years), and her granduncle also died at the age of 40. DNA analysis shows that the proband had the 236T $\rightarrow \mathrm{C}$ nucleotide alteration. This transition was observed in codon 79, and converted an isoleucine residue to a threonine residue (Fig. 5a). Ile79Thr occurred in conserved residues found in TNNT2 orthologues of human, mouse, rat, cat, and 
Fig. 3 Pedigree and phenotype of Family C. Pedigree with four generations (Roman Numerals), the propositus is denoted by an arrow. Further clinical data for family members is detailed in the table. HCM hypertrophic cardiomyopathy, WPW syndrome Wolff-ParkinsonWhite syndrome

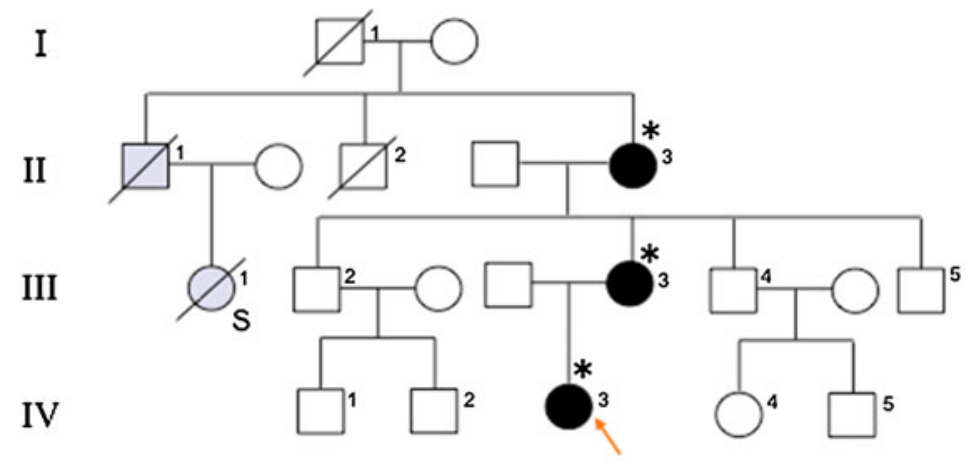

: proband

$\square$ : hypertrophic cardiomyopathy
$\square \quad$ : asymptomatic proband
: hypertrophic cardiomyopathy suspected
: normal allele
S : mutation allele Arg92Trp
: sudden death

Phenotype

II -1 Died at age 60 years due to heart disease II $-3 \mathrm{HCM}$, Atrial fibrillation, Pulmonary hypertension III-3 HCM, WPW syndrome (type C)

IV-3 HCM, West syndrome (due to perinatal brain damage)

Fig. 4 Pedigree and phenotype of Family D. Pedigree with four generations (Roman Numerals), the propositus is denoted by an arrow. Further clinical data for family members is detailed in the table. HCM hypertrophic cardiomyopathy, $V f$ ventricular fibrillation

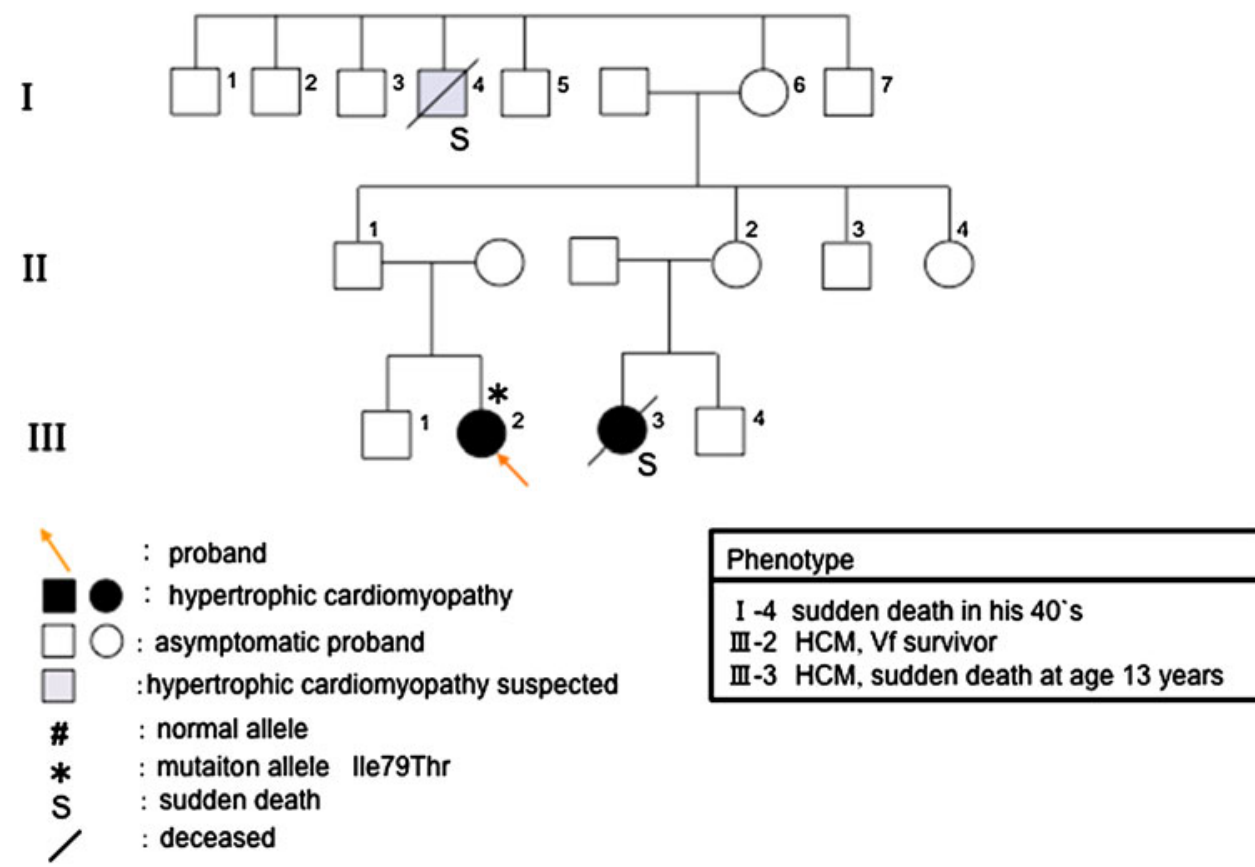

ox (Fig. 5b). This mutation was not observed in 363 chromosomes from unaffected Japanese populations. The proband (Fig. 4; III-2) also had a 5-bp (CTTCT) deletion/ deletion polymorphism of intron 3 of TNNT2 (Fig. 6a).

To clarify the clinical importance of this polymorphism, we performed genetic analysis in $47 \mathrm{HCM}$ patients from 173 unrelated Japanese patients with familial HCM. In these 47 patients, 24 had the deletion/deletion polymorphism (51 \%, 14 men and 10 women; 0-72 years old, median age 30 years old). Five of the $24(21 \%)$ patients who had the deletion/deletion polymorphism were diagnosed with apical HCM or HOCM. In 6 of the $10(60 \%)$ with available data of echocardiography among these 24 patients, the maximum wall thickness was more than 30 $\mathrm{mm}$. On the other hand, in the $47 \mathrm{HCM}$ patients, the remaining 23 did not have the deletion/deletion polymorphism, but had the deletion/insertion or insertion/insertion polymorphism (49\%, 15 men and 8 women; 0-76 years old, median age 18 years). Two of the 23 (9\%) patients were diagnosed with apical HCM, and there were no 
a Proband (Exon 8)
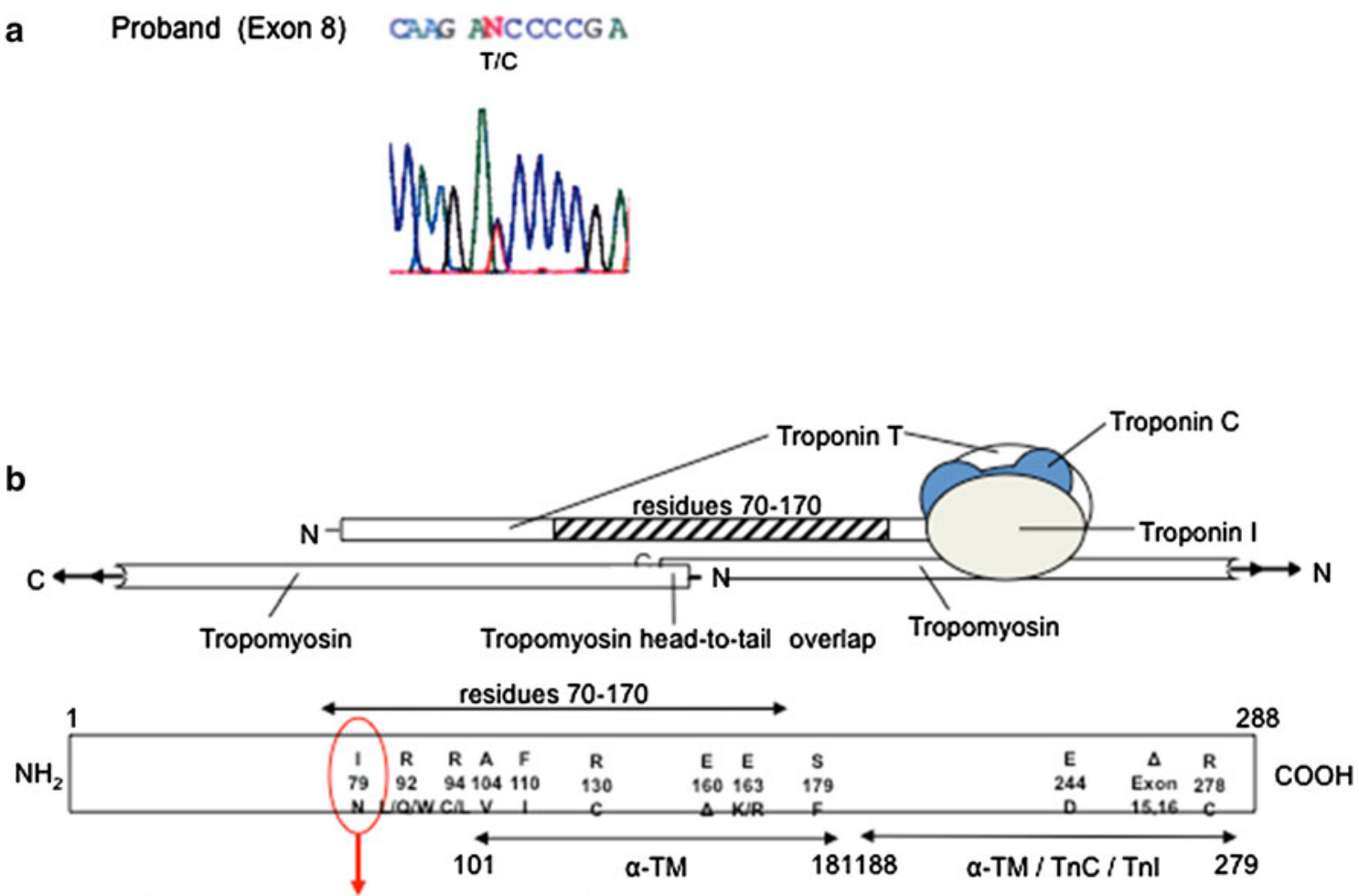

\begin{tabular}{c|llll} 
hunan v1 & N L V P P K I P D G E R V \\
human V2 & N L V P P K I & P D G E R V \\
mouse & N L V P P K I & P D G E R V \\
rat & N L V P P K I & P D G E R V \\
cat & N L V P P K I & P D G E R V \\
dog & N L V P P K I & P D G E R V \\
ox & N L V P P K I & P D G E R V
\end{tabular}

Fig. 5 a The new Ile79Thr mutation of TNNT2 (Exon 8). b The position of the 79th Ile codes for the binding site of tropomyosin. This domain is well preserved in mammals

HOCM patients. Two of the seven (29\%) with available data of echocardiography among these 23 patients showed the maximum wall thickness of more than $30 \mathrm{~mm}$.

\section{Discussion}

Previous studies have reported familial HCM cases where a consistent relationship between certain genetic mutations and clinical outcome was observed, allowing for the classification of "benign" and "malignant" mutations [18-30].

However, in recent years it was considered that the specific gene mutation cannot be the sole factor that dictates clinical phenotype. Since around 1\%-2\% of all patients with HCM had a "benign" or "malignant" mutation, mutation type was not seen to be clinically useful in predicting prognosis in $\mathrm{HCM}$ given this very low incidence rate [32, 38-40]. In addition, it was reported that mutation of a sarcomeric protein gene can cause RCM, HCM, and DCM within the same family, and patients with a benign mutation experienced a very serious clinical course [41, 42].

In the present study, the phenotype of each family was often different from reported cases, even if they had the same genetic mutation. In addition, families with the same genetic mutation showed a similar trend in the phenotype, but it was not exactly the same. However, sudden death in youth was observed in all of these families. On the other hand, there seemed to be a family with a "malignant" mutation, which did not show the phenotype of HCM or a family history of sudden death.

For example, in family A, two TNNT2 mutations were found, the Arg130 Cys and Phe110Ile mutations. The Arg130 Cys mutation has been reported by a Chinese research group [21], whose clinical features had an early onset, syncope, sudden death in youth, heart failure, and arrhythmia as atrial fibrillation. The Phe110Ile mutation has been reported to show a favorable prognosis, and have comparatively slight hypertrophy or apical hypertrophy 


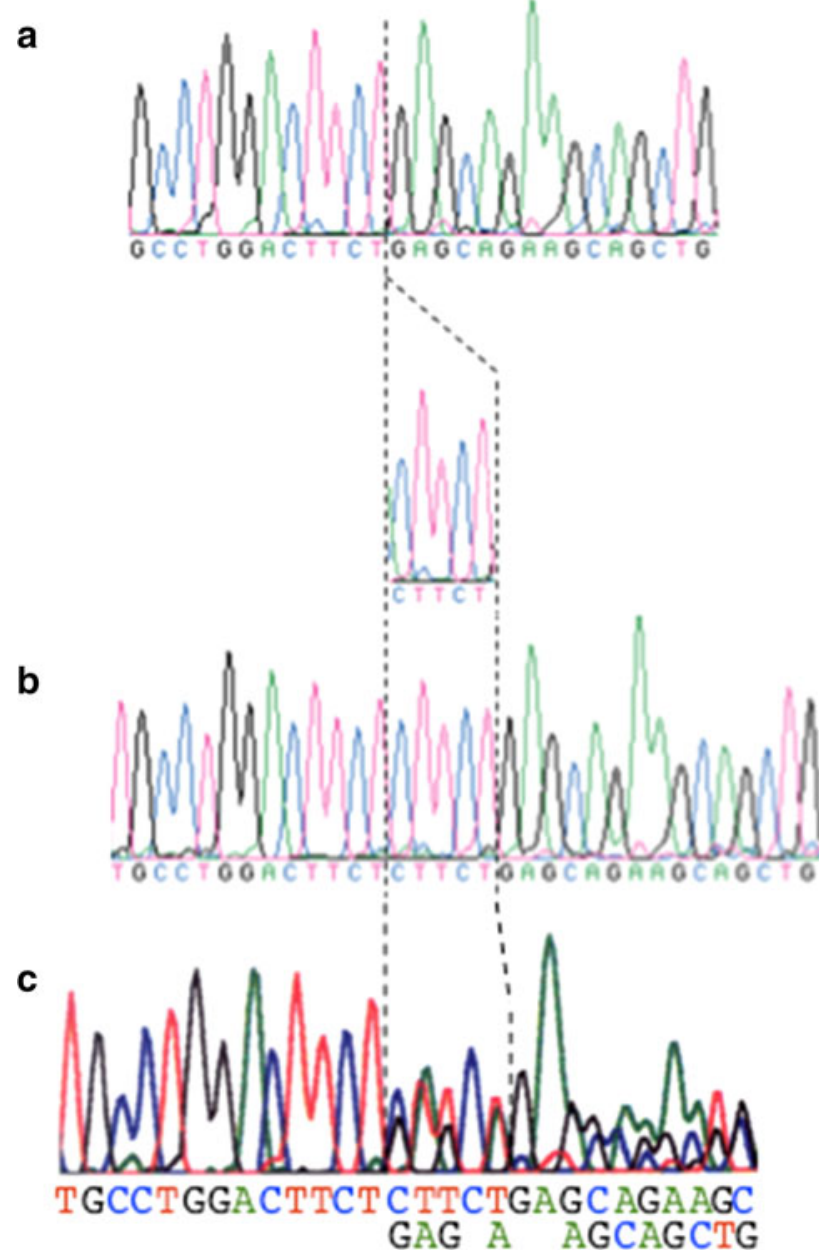

Fig. 6 a The deletion/deletion(D/D) polymorphism. b The insertion/ insertion (I/I) polymorphism. c The insertion/deletion (I/D) polymorphism

(in 16 individuals of 6 Japanese Families) [19, 20]. Both of these reported pedigrees are Asian.

In family A, whereas the proband and her elder brother, who carried these two mutations, showed similar reported phenotypes of the Arg130 Cys mutation [21], her mother and mother's family members, who had the Arg130Cys mutation, showed no abnormal clinical features such as cardiac hypertrophy, sudden death, or abnormal electrocardiograms. Furthermore, her father and father's family members, who had the Phe110Ile mutation, showed atrioventricular blocks, and these phenotypes have not been reported.

In family $\mathrm{B}$, an Arg92Trp mutation of TNNT2 was found. The mutation showed comparatively slight cardiac hypertrophy or a high incidence of sudden death in males (19 individuals of two mixed racial families) [22-24]. However, the proband and her family, who carried HCM, showed relatively severe cardiac hypertrophy, with a high incidence of sudden death in females.
In family $\mathrm{C}$, an $\mathrm{Arg} 92 \mathrm{Trp}$ mutation was also found. The proband and her family, who carried HCM, showed mild cardiac hypertrophy and asymmetric septal hypertrophy. The proband's myocardial hypertrophy had been gradually increasing, and her mother had a suspected shift to the dilated phase.

In family $\mathrm{D}$, the proband carried the new mutation Ile79Thr of TNNT2. She survived following an episode of Vf, and her cousin died suddenly at the age of 13 years. Previously, a mutation of the 79 residue, the Ile79Asn mutation, had been reported [24, 25], and this mutation also showed a poor prognosis. In our mutated case, even if the amino acid mutation (Ile79Thr) was different from the reported case (Ile79Asn), the patient showed a malignant prognosis. In family D, a 5-base-pair (CTTCT) deletion/ deletion (D/D) polymorphism in intron 3 of the TNNT2 was also found. It has been reported that this polymorphism had caused skipping of exon 4 of TNNT2, and that the deletion allele could be associated with a predisposition for prominent LVH [42]. Although it was in a very limited range, from our genetic study on this polymorphism we gained the impression that a patient carrying the TNNT2 deletion/ deletion polymorphism had a stronger tendency toward hypertrophy. To conduct further analysis, further examination including new cases is required.

We considered that, at least in Japanese familial HCM, only the type of genetic mutation of TNNT2 did not seem useful in distinguishing the prognosis. However, if mutations were found, there was a risk of sudden death in youth. Therefore, regardless of the type of genetic mutation, it would be more important to observe the patient in detail from birth in each lineage.

The development of a "case-based" method would be useful to treat and help each individual, and more attention needs to be paid toward searching for the modifier and environmental factors including diet, lifestyle, exercise, and the modification gene and polymorphism.

Acknowledgments This work was supported by the Encouraging Development of Strategic Research Centers, Special Coordination Funds for Promoting Science and Technology, Ministry of Education, Culture, Sports, Science, and Technology, Japan. We would like to thank Michiko Furutani and Yoshiyuki Furutani for preparation of the manuscript.

Open Access This article is distributed under the terms of the Creative Commons Attribution License which permits any use, distribution, and reproduction in any medium, provided the original author(s) and the source are credited.

\section{References}

1. Cirino AL, Ho C (2009) Familial hypertrophic cardiomyopathy overview. Gene Rev. http://www.ncbi.nlm.nih.gov/books/ NBK1768/ 
2. Maron BJ (1997) Hypertrophic cardiomyopathy. Lancet 350:127-133

3. Seidman JG, Sideman C (2001) The genetic basis for cardiomyopathy: from mutation identification to mechanistic paradigms. Cell 104:557-567

4. Spirito P, Sideman CE, McKenna WJ, Maron BJ (1997) The management of hypertrophic cardiomyopathy. N Engl J Med 1336:775-785

5. Marian AJ, Roberts R (2001) The molecular genetic bases for hypertrophic cardiomyopathy. J Mol Cell Cardiol 33:655-670

6. Nakashima K, Kusakawa I, Yamamoto T, Hirabayashi S, Hosoya R, Shimizu W, Sumitomo N (2013) A left ventricular noncompaction in a patient with long QT syndrome caused by a $K C N Q 1$ mutation: a case report. Heart Vessels 28:126-129

7. Erdmann J, Daehmlow S, Wischke S, Senyuva M, Werner U, Raible J, Tanis N, Dyachenko S, Hummel M, Hetzer R, RegitzZagrosek V (2003) Mutation spectrum in a large cohort of unrelated consecutive patients with hypertrophic cardiomyopathy. Clin Genet 64(4):339-349

8. Forissier JF, Carrier L, Farza H, Bonne G, Bercovici J, Richard P, Hainque B, Townsend PJ, Yacoub MH, Faure S, Dubourg O, Millaire A, Hagege AA, Desnos M, Komajda M, Schwartz K (1996) Codon 102 of the cardiac troponin T gene is a putative hot spot for mutations in familial hypertrophic cardiomyopathy. Circulation 94:3069-3073

9. Fujino N, Shimizu M, Ino H, Yamaguchi M, Yasuda T, Nagata M, Konno T, Mabuchi H (2002) A novel mutation Lys273Glu in the cardiac Troponin T gene shows high degree of penetrance and transition from hypertrophic to dilated cardiomyopathy. Am J Cardiol 89:29-33

10. Niimura H, Patton KK, McKenna WJ, Soults J, Maron BJ, Seidman JG, Seidman CE (2002) Sarcomere protein gene mutations in hypertrophic cardiomyopathy of the elderly. Circulation 105:446-451

11. MatsushitaY Furukawa T, Kasanuki H, Nishibatake M, Kurihara Y, Ikeda A, Kamatani N, Takeshima H, Matsuoka R (2007) Mutation of junctophilin type 2 associated with hypertrophic cardiomyopathy. J Hum Genet 52:543-548

12. de Tombe PP (2003) Cardiac myofilaments: mechanics and regulation. J Biomech 36:721-730

13. Harada K, Potter JD (2004) Familial hypertrophic cardiomyopathy mutations from different functional regions of Troponin $\mathrm{T}$ result in different effects on the $\mathrm{pH}$ and $\mathrm{Ca}^{2+}$ sensitivity of cardiac muscle contraction. J Biol Chem 279(15):14488-14495

14. Lassalle MW (2010) Defective dynamic properties of human cardiac troponin $\mathrm{T}$ mutations. Biosci Biotechnol Biochem 74(1):82-91

15. Palm T, Graboski S, Hitchcick-DeGregori SE, Greenfield NJ (2001) Disease-causing mutations in cardiac Troponin T: identification of a critical tropomyosin-binding region. Biophys $\mathrm{J}$ 81:2827-2837

16. Redwood CS, Moolman-Smook JC, Watkins H (1999) Properties of mutant contractile proteins that cause hypertrophic cardiomyopathy. Cardiovasc Res 44:20-36

17. Uchino T, Isomoto S, Noguchi T, Ono K (2013) Window current through the T-type $\mathrm{Ca}^{2+}$ channel triggers the mechanism for cellular apoptosis via mitochondrial pathways. Heart Vessels. doi:10.1007/s00380-012-0316-8

18. Gomes AV, Barnes JA, Harada K, Potter JD (2004) Role of troponin $\mathrm{T}$ in disease. Mol Cell Biochem 263:115-129

19. Anan R, Shono H, Kisanuki A, Arima S, Nakano S, Tanaka H (1998) Patients with familial hypertrophic cardiomyopathy caused by a Phe110Ile missense mutation in the cardiac troponin $\mathrm{T}$ gene have variable cardiac morphologies and a favorable prognosis. Circulation 98:391-397
20. Nakaura H, Yanaga F, Ohtsuki I, Morimoto S (1999) Effects of missense mutations Phe110Ile and Glu244Asp in human cardiac troponin $\mathrm{T}$ on force generation in skinned cardiac muscle fibers. J Biochem 126(3):457-460

21. Song L, Zou Y, Wang J, Zhen Y, Lou K, Zhang Q, Wang X, Wang H, Li J, Hui R (2005) Mutations profile in Chinese patients with hypertrophic cardiomyopathy. Clin Chim Acta 351:209-216

22. Moolman-Smook JC, De Lange WJ, Bruwer ECD, Brink PA, Corfield VA (1999) The origins of hypertrophic cardiomyopathycausing mutations in two South African subpopulations: a unique profile of both independent and founder events. Am J Hum Genet 65(5):1308-1320

23. Moolman JC, Corfield VA, Posen B, Ngumbela K, Watokins H (1997) Sudden death due to troponin T mutations. J Am Coll Cardiol 29:549-555

24. Thierfelder L, Watkins H, MacRae C, Lamas R, McKenna W, Vosberg HP, Seidman CE (1994) $\alpha$-Tropomyosin and cardiac troponin $\mathrm{T}$ mutations cause familial hypertrophic cardiomyopathy: a disease of the sarcomere. Cell 77:701-712

25. Watkins H, McKenna W, Thierfelder L, Suk HJ, Anan R, O’Donogue A, Spirito P, Matsumori A, Moravec CE, Seidman JG (1995) Mutations in the genes for cardiac troponin $T$ and a-tropomyosin in hypertrophic cardiomyopathy. N Engl J Med 332:1058-1064

26. Xu Q, Dewey S, Nguyen S, Gomes AD (2010) Malignant and benign mutations in familial cardiomyopathies: insights into mutations linked to complex cardiovascular phenotypes. J Mol Cell Cardiol 48:899-909

27. Mörner S, Richard P, Kazzam E, Hellman U, Hainque B, Schwartz K, Waldenström A (2003) Identification of the genotypes causing hypertrophic cardiomyopathy in northern Sweden. J Mol Cell Cardiol 35(7):841-849

28. Varnava A, Baboonian C, Davison F, de Cruz, Elliot PM (1999) A new mutation of the cardiac troponin $\mathrm{T}$ gene causing familial hypertrophic cardiomyopathy without left ventricular hypertrophy. Heart 82(5):621-624

29. Nakajima-Taniguchi C, Matsui H, Fujio Y, Nagata S, Kishimoto T, Yamauchi-Takihara K (1997) Novel missense mutation in cardiac troponin $\mathrm{T}$ gene found in Japanese patient with hypertrophic cardiomyopathy. J Mol Cell Cardiol 29:839-843

30. Ho CY, Lever HM, DeSanctis R, Farver CF, Seidman JG, Seidman CE (2000) Homozygous mutation in cardiac troponin T: implications for hypertrophic cardiomyopathy. Circulation 102(16): 1950-1955

31. Hen Y, Iguchi N, Machida H, Takada K, Utanohara Y (2012) High signal intensity on T2-weighted cardiac magnetic resonance imaging correlates with the ventricular tachyarrhythmia in hypertrophic cardiomyopathy. Heart Vessels. doi:10.1007/ s00380-012-0300-3

32. Landstrom Andrew P, Ho Carolyn Y, Ackerman Michael J (2010) Mutation type is not clinically useful in predicting prognosis in hypertrophic cardiomyopathy. Circulation 2010(122): 2441-2450

33. Yoshida MC, Satoh H, Sasaki M, Semba K, Yamamoto T, Toyoshima K (1986) Regional location of novel yes-related proto-oncogene, syn, on human chromosome 6 at band q21. Jpn J Cancer Res 77:1059-1061

34. Berg JN, Gallione CJ, Stenzel TT, Johnson DW, Allen WP, Schwartz CE, Jackson CE, Porteous M, Marchuket D (1997) The activin receptor-like kinase 1 gene: genomic structure and mutations in hereditary hemorrhagic telangiectasia type 2 . Am J Hum Genet 61:60-67

35. Deng Z, Morse JH, Slager SL, Cuervo N, Moore KJ, Venetos G, Kalachikov S, Cayanis E, Fischer SG, Barst RJ, Hodge SE, Knowles JA (2000) Familial primary pulmonary hypertension 
(gene PPH1) is caused by mutations in the bone morphogenetic protein receptor-II gene. Am J Hum Genet 67:737-744

36. Tanus-Santos JE, Desai M, Flockhart DA (2001) Effects of ethnicity on the distribution of clinically relevant endothelial nitric oxide variants. Pharmacogenetics 11:719-725

37. Rigat B, Hubert C, Corvol P, Soubrier F (1992) PCR detection of the insertion/deletion polymorphism of the human angiotensin converting enzyme gene (DCP1) (dipeptidyl carboxypeptidase 1). Nucleic Acids Res 20(6):1433

38. Van Driest SL, Ommen SR, Tajik AJ, Gersh BJ, Ackerman MJ (2005) Yield of genetic testing in hypertrophic cardiomyopathy. Mayo Clin Proc 80:739-744

39. Van Driest SV, Ackerman MJ, Ommen SR, Shakur R, Will ML, Nishimura RA, Tajik AJ, Gersh BJ (2002) Prevalence and severity of "benign" mutations in the beta myosin heavy chain, cardiac troponin- $\mathrm{T}$, and alpha tropomyosin genes in hypertrophic cardiomyopathy. Circulation 106:3085-3090

40. Ackerman MJ, Van Driest SV, Ommen SR, Will ML, Nishimura RA, Tajik AJ, Gersh BJ (2002) Prevalence and age-dependence of malignant mutations in the beta-myosin heavy chain and troponin $\mathrm{T}$ gene in hypertrophic cardiomyopathy: a comprehensive outpatient perspective. J Am Coll Cardiol 39:2042-2048

41. Menon S, Michels V, Pellikka P, Ballew J, Karst M, Herron K, Nelson S, Rodeheffer R, Olson T (2008) Cardiac troponin T mutation in familial cardiomyopathy with variable remodeling and restrictive physiology. Clin Genet 74:445-454

42. Komamura K, Iwai N, Kokame K, Yasumura Y, Kim J, Yamagishi M, Tomoike H, Kitakaze M, Miyatake K (2004) The role of a common TNNT2 polymorphism in cardiac hypertrophy. J Hum Genet 49:129-133 